\title{
Human Norepinephrine Metabolism
}

\author{
ITS EVALUATION BY ADMINISTRATION OF \\ TRITIATED NOREPINEPHRINE
}

\author{
Stanley E. Gitlow, Milton Mendlowitz, Laura M. Bertani, \\ SHERWIN WILK, and ElIzABETH K. WIIK \\ From the Department of Medicine, Mount Sinai School of Medicine, \\ New York 10029
}

\begin{abstract}
A в S T R A C T It has become increasingly apparent that evaluation of human norepinephrine metabolism simply by assay of catecholamines in urine is inadequate for differentiation of many physiological or pathological states. In an attempt to examine norepinepherine metabolism in the human subject, tritium-labeled $d, l$-norepinephrine was administered to 11 normal adults and the definitive turnover rates and relative specific activities of norepinephrine and its major catabolites, vanillylmandelic acid, 3-methoxy-4-hydroxyphenylethyleneglycol, and normetanephrine, as well as the cumulative 24 $\mathrm{hr}$ isotope excretion were determined. The major endogenous norepinephrine catabolites were also quantitatively assayed. In order to verify the reliability of the isotope label, parallel studies were carried out in two patients to whom norepinephrine $-{ }^{14} \mathrm{C}$ was administered. Metabolic studies were repeated after the administration of reserpine to gain further insight into the distribution of the label.
\end{abstract}

All studies demonstrated a consistent difference between the relative specific activities of the amines and their deaminated congeners, thereby indicating an uneven distribution of the labeled material. The marked decrease in the relative specific activities of the deaminated catabolites after the administration of reserpine showed that the present experimental technique succeeded in labeling, though to a limited extent, the storage or reserpine-releasable pool. A dose of reserpine known to interfere with sympathetic activity but failing to elicit a change in excretion of endogenous catecholamine catabolites, nonetheless resulted in a marked abnormality in the metabolic handling of labeled norepinephrine. It is anticipated that such studies may not only be of value in measuring sympathetic activity in the intact human

Received for publication 14 September 1970 and in revised form 23 November 1970. subject during physiologic variations and pathologic states associated with abnormalities in catecholamine metabolism, but may serve as a technique whereby drugs that affect human norepinephrine metabolism may undergo precise pharmacologic evaluation.

\section{INTRODUCTION}

Although evaluation of human adrenergic activity was considerably advanced by the discovery and measurement of norepinephrine $(\mathrm{NE})^{1}$ and its catabolites in human plasma or urine, these biochemical techniques often lacked the sensitivity to elucidate subtle physiologic changes, pathologic variations, or abnormalities resulting from drug administration (1-4). By 1959, it was apparent that injected, labeled catecholamines were only degraded and excreted in part, and that a significant fraction was stored intact $(5,6)$. At that time, d,l-7$\mathrm{NE}-{ }^{3} \mathrm{H}$ with high specific activity became available, and by the following year evidence had accumulated pointing to its incorporation into $\mathrm{NE}$ stores after administration to human subjects $(7,8)$.

Diverse animal studies during the ensuing $5 \mathrm{yr}$ demonstrated that administration of a labeled catecholamine was followed by its incorporation into NE stores within the sympathetic neurons (9-13), the rate of release of the labeled material being dependent upon sympathetic activity (14). Simultaneous pharmacologic experiments suggested the existence of at least two storage mechanisms, one released by tyramine and preferentially catabolized to O-methylated derivatives, the other released by reserpine and preferentially catabolized to amine-

\footnotetext{
${ }^{1}$ Abbreviations used in this paper: DOPA, 3,4-dihydroxyphenylalanine; G, 3-methoxy-4-hydroxyphenylethyleneglycol ; HVA, homovanillic acid; $\mathrm{NE}$, norepinephrine; NM, normetanephrine; VMA, vanillylmandelic acid.
} 
oxidized substances $(11,12)$. Similarly, circulating catecholamines were catabolized preferentially to 3-Omethylated derivatives (15) whereas intraneuronal $\mathrm{NE}$ catabolism favored formation of the amine-oxidized products (16).

The degree to which intravenously administered NE${ }^{3} \mathrm{H}$ mixed with endogenously synthesized $\mathrm{NE}$ in the intact human subject could therefore be evaluated by determination of the relative specific activities of $\mathrm{NE}$ metabolites (17). Simultaneously, such measurements might yield information concerning tissue turnover rates (18, 19). Administration of reserpine, a drug capable of modifying that $\mathrm{NE}$ storage mechanism favoring the catabolic pathways leading to amine-oxidized products, would not only yield information regarding distribution of the $\mathrm{NE}-{ }^{3} \mathrm{H}$ but might allow evaluation of a method for determining the functional status of the NE storage granule in the intact human subject.

In order to obtain a more complete biochemical picture of human sympathetic activity, urine specimens from the experimental subjects were assayed for the major endogenous $\mathrm{NE}$ metabolites: $\mathrm{NE}$, normetanephrine (NM), vanillylmandelic acid (VMA), and 3-methoxy-4hydroxyphenylethyleneglycol $(G)$. The turnover rates and degree of labeling of the NE pools as judged by the relative specific activities of the $\mathrm{NE}$ metabolites were also determined. Such studies of normal human subjects may hereafter serve as a reference for examination of disturbed physiologic states as well as for pharmacologic studies of drugs known to modify sympathetic function.

\section{METHODS}

A racemic mixture of $d, l-7-\mathrm{NE}-{ }^{8} \mathrm{H}^{2}$ (20) in a dose of 1.5 $\mu \mathrm{g}$ per $\mathrm{kg}$ of body weight was diluted in $250 \mathrm{ml}$ of $5 \%$ glucose in water, administered intravenously for $1 \mathrm{hr}$ by a constant-rate infusion pump to nine male and two female normal adult subjects between 16 and $54 \mathrm{yr}$ of age, and urine samples collected $1,2,4,8,12,18,24,36,48,60,72$, $84,96,108,120,132,144,156$, and $168 \mathrm{hr}$ after the initiation of the infusion. All experimental subjects maintained their normal diet and activity, but avoided alcohol and other drugs except as noted in the experimental protocol. Each urine sample was acidified and stored at $0^{\circ} \mathrm{C}$ until assayed in the following manner.

1. Creatinine content was determined according to the Jaffé technique (21).

2. Total tritium content of duplicate samples was determined by dilution ( $1 \mathrm{ml}$ urine to $100 \mathrm{ml}$ with water), and liquid scintillation counting with a Packard Tri-Carb model 3320 Spectrometer using dioxane : naphthalene : 2,5-diphenyloxazole : 1,4-bis-(5-phenyloxazolyl-2) benzene. Counting levels in excess of four times background and reproducibility

${ }^{2} d, l-7-\mathrm{NE}-{ }^{3} \mathrm{H}$ (SA $4225 \mathrm{mCi} / \mathrm{mmole}$ ); New England $\mathrm{Nu}-$ clear Corp., Boston, Mass. $d, l-7-\mathrm{NE}-{ }^{14} \mathrm{C}$ (SA $43 \mathrm{mCi}$ / mmole); New England Nuclear Corp., Boston, Mass. of $0.1 \%$ were attained in all specimens. All radioactive measurements were corrected to $\mathrm{dpm}$ and counting efficiencies were determined by the addition of internal standards to duplicate specimens.

3. NE content of urine specimens was determined by the Anton and Sayre technique (22) modified by reducing the amount of alumina eluate aliquot for the fluorescence assay to $0.1 \mathrm{ml}$ and utilizing acetate buffer at $\mathrm{pH} 3.5$ and phosphate buffer at 7.0 for the differential determination of $\mathrm{NE}$ in the presence of epinephrine. The alumina eluate contained a single radioactive substance possessing the same $R_{f}$ as $\mathrm{NE}$ when chromatographed on paper in two systems,- - butanol: acetic acid: water $(4: 1: 1)$ or propionic acid: benzene : water $(14: 20: 1)$. Ethyl acetate failed to extract significant radioactivity from the alumina eluates. The $\mathrm{NE}-{ }^{3} \mathrm{H}$ content of duplicate samples was reproducible within $\pm 5 \%$.

4. The VMA content was determined by bidirectional paper chromatography $(2,3,23)$ and gas-liquid chromatography (24). These procedures were not only highly specific, but yielded reproducibility of duplicate specimens to within $\pm 10 \%$. Labeled VMA was assayed in the ethyl acetate extract of the acidified urine. $95 \%$ of the VMA added to the urine sample was consistently recovered in the ethyl acetate extract, the radioactivity of which possessed the $R_{f}$ of authentic VMA when chromatographed on paper in two phases (isopropanol:ammonia: water [40:9:1] and benzene: propionic acid: water $[14: 20: 1])$.

5. NM was determined by a modification (25) of the Taniguchi technique (26). The borate buffer eluate contained in excess of $95 \%$ of the labeled NM which when chromatographed on paper in isopropanol:ammonia: water (40:9:1) gave a single radioactive peak corresponding to the $R_{f}$ of authentic NM.

6. G content was assayed by the Wilk gas-liquid chromatographic technique (27) and the labeled trifluoroacetylated derivative counted and corrected for a recovery of $\mathrm{G}$ in the final solution of $55 \%( \pm 6 \%)$. Paper chromatography of the final ethyl acetate extract before derivatization in isopropanol: ammonia: water $(40: 9: 1)$ and benzene: propionic acid: water $(14: 20: 1)$ revealed a single radioactive peak with the same $R_{f}$ as authentic $G$.

The content of total metanephrines in a small number of urine samples was determined by the modified Pisano technique $(4,23)$. Specificity was assured by chromatography of the Amberlite CG-50 resin eluate on paper in isopropanol: ammonia: water $(40: 9: 1)$. Specific activities were obtained by eluting from the paper, counting and oxidizing the eluate for photometric assay. The radioactive peak possessed the same $R_{f}$ as authentic NM.

Homovanillic acid (HVA) was measured by paper chromatography (23) in urine samples from three patients who were studied before and during $3 \mathrm{wk}$ of treatment with 0.5-1.5 mg reserpine per day. Duplicate studies were also performed in three patients who received no drug.

Two subjects received $0.02 \mu \mathrm{g}$ of $d, l-\mathrm{NE}-{ }^{14} \mathrm{C}$ intravenously/ $\mathrm{kg}$ of body weight per min for $1 \mathrm{hr}$ instead of the tritiumlabeled NE. But for the use of larger portions and occasional concentration of samples or eluates by flash evaporation, the collections and assays were performed as noted for the $\mathrm{NE}-{ }^{3} \mathrm{H}$ studies.

Specific activity values for the catabolites were charted at the midpoint of each collection period and the best fitting line determined by the least squares method. Relative specific activities of the various catabolites were compared at a point $60 \mathrm{hr}$ after the start of the $\mathrm{NE}-{ }^{8} \mathrm{H}$ (or $\mathrm{NE}-{ }^{14} \mathrm{C}$ ) infusion. 
TABLE I

Results of Administration of $N E-{ }^{3} \mathrm{H}$ or $N E-{ }^{14} \mathrm{C}$ to Normal Human Volunteers

\begin{tabular}{|c|c|c|c|c|c|c|c|c|c|c|c|c|c|c|c|c|}
\hline \multirow{2}{*}{$\begin{array}{l}\text { Pa- } \\
\text { tient }\end{array}$} & \multirow[b]{2}{*}{ Age } & \multirow[b]{2}{*}{ Sex } & \multirow{2}{*}{$\begin{array}{l}24 \mathrm{hr} \\
\text { cumulative } \\
\text { excretion }\end{array}$} & \multicolumn{3}{|c|}{$\begin{array}{l}\text { Specific activity } \\
\text { relative to } G(60 \\
\text { hr postinfusion) }\end{array}$} & \multicolumn{5}{|c|}{$T_{1}$ of third component } & \multicolumn{5}{|c|}{ Endogenous metabolites* } \\
\hline & & & & VMA & NM & $\mathrm{NE}$ & G & VMA & NM & $\mathrm{NE}$ & Mean & G & VMA & NM & $\mathrm{NE}$ & HVA \\
\hline & $y r$ & & $\%$ & \multicolumn{3}{|c|}{$d p m / m \mathbf{M}$} & \multicolumn{5}{|c|}{$h r$} & \multicolumn{5}{|c|}{$\mu g / m g$ creatinine } \\
\hline 1 & 32 & F & 79 & 2.82 & 4.12 & 14.58 & 28.0 & 27.5 & 27.0 & 32.0 & 28.6 & 1.14 & 0.94 & 0.067 & 0.036 & 2.10 \\
\hline 2 & 26 & $\mathbf{M}$ & 67 & 1.23 & 3.09 & 3.53 & 28.5 & 29.0 & 27.0 & 26.5 & 27.8 & 1.11 & 1.42 & 0.062 & 0.051 & \\
\hline 3 & 24 & $\mathrm{~F}$ & 96 & 2.61 & 9.01 & 20.02 & 20.0 & 19.5 & 21.0 & 23.0 & 20.9 & 1.29 & 1.55 & 0.074 & 0.016 & \\
\hline 4 & 22 & $\mathbf{M}$ & 54 & 1.36 & 5.34 & 6.02 & 22.5 & 24.0 & 19.5 & 22.5 & 22.1 & 1.30 & 1.20 & 0.085 & 0.020 & \\
\hline 5 & 49 & $\mathbf{M}$ & 71 & 0.55 & 1.95 & 4.30 & 24.0 & 24.5 & 21.0 & 23.0 & 23.1 & 0.43 & 1.01 & 0.079 & 0.019 & \\
\hline 6 & 39 & $\mathbf{M}$ & 65 & 1.00 & 3.76 & 29.60 & 22.0 & 22.0 & 24.0 & 25.0 & 23.3 & 2.00 & 2.00 & 0.120 & 0.020 & \\
\hline 7 & 54 & $\mathbf{M}$ & 73 & 1.14 & 3.73 & 4.02 & 18.0 & 19.0 & 20.0 & 31.0 & 22.0 & 0.68 & 0.87 & 0.150 & 0.014 & 0.75 \\
\hline 8 & 32 & $\mathbf{M}$ & 51 & 2.92 & 10.83 & 16.67 & 21.0 & 20.0 & 28.0 & 30.5 & 24.5 & 1.20 & 1.25 & 0.091 & 0.020 & \\
\hline 9 & 20 & $\mathbf{M}$ & 62 & 1.63 & 4.06 & 20.00 & 27.5 & 28.0 & 28.0 & 28.5 & 28.0 & 0.77 & 1.16 & 0.074 & 0.026 & 1.21 \\
\hline $10 \ddagger$ & 16 & $\mathbf{M}$ & 72 & 2.19 & 11.95 & 16.80 & 24.0 & 24.0 & 26.0 & 26.0 & 25.0 & 0.67 & 0.90 & 0.124 & 0.009 & 1.14 \\
\hline $11 \ddagger$ & 39 & F & 75 & 1.48 & 2.61 & 2.78 & 21.0 & 19.0 & 20.0 & 20.0 & 20.0 & 0.79 & 0.39 & 0.091 & 0.016 & \\
\hline 12 & 54 & $\mathbf{M}$ & 75 & 2.36 & 13.11 & 32.43 & 17.0 & 17.0 & 17.0 & 17.0 & 17.0 & 0.94 & 1.61 & 0.109 & 0.020 & 1.50 \\
\hline 13 & 40 & $\mathbf{M}$ & 57 & 4.00 & 8.53 & 12.52 & 22.0 & 22.0 & 21.0 & 24.0 & 22.3 & 1.19 & 1.22 & 0.106 & 0.016 & \\
\hline Mean & & & 69 & 1.95 & 6.32 & 14.10 & 22.7 & 22.7 & 23.0 & 25.3 & 23.4 & 1.04 & 1.19 & 0.095 & 0.022 & 1.34 \\
\hline SD ( $( \pm)$ & & & 12 & 0.97 & 3.85 & 9.86 & 3.6 & 3.8 & 3.8 & 4.4 & 3.4 & 0.40 & 0.41 & 0.026 & 0.011 & 0.50 \\
\hline
\end{tabular}

* Each value is the mean of assays of 10 different urine aliquots ( $\mu \mathrm{g} / \mathrm{mg}$ creatinine).

$\ddagger$ Patients receiving NE-14C.

\section{RESULTS}

Infusion of the $\mathrm{NE}-{ }^{3} \mathrm{H}$ failed to elicit objective or subjective changes in any recipient. During the first $24 \mathrm{hr}$ after the NE- ${ }^{-} \mathrm{H}$ infusion, a mean of $69 \% \pm 12$ (SD) of the radioactive label was excreted in the urine (Table I). A typical example of cumulative excretion of isotope during this period is illustrated in Fig. 1. The pattern of isotope excretion following $\mathrm{NE}-{ }^{14} \mathrm{C}$ administration was similar to that noted after $\mathrm{NE}-{ }^{-} \mathrm{H}$ (Table I).

The mean specific activity of the four metabolites in urine (VMA, G, NM, NE) reached a peak within a few hours of the infusion and then declined in a fashion which could be expressed as the sum of at least three exponential functions possessing mean $\mathrm{T}_{3}^{3}$ values of 1.19 $\mathrm{hr}(0.5-2.0), 5.22 \mathrm{hr}(2.5-7.5)$, and $23.43 \mathrm{hr}(17.0-$ 28.6) (Fig. 2). The definitive (third component) exponential decline of specific activity was achieved approximately $40 \mathrm{hr}$ after the $\mathrm{NE}^{8} \mathrm{H}$ infusion. Measurement of this exponent for up to nine days failed to reveal a slower component. The final exponential declines of the specific activities of the individual catabolites excreted by each patient were approximately parallel (Fig. 3, Table I) but the relative specific activities of the metabolites differed in a consistent manner, with $G$ representing the lowest value and in ascending order, VMA, NM and NE. The specific activity of the $\mathrm{NM}$ exceeded that of the deaminated catabolites by a factor of such magnitude $(5: 1)$ as to make it unlikely that such a differential could be accounted for by the

${ }^{3}$ Turnover time $=\mathrm{T} \frac{1}{2}=$ the time necessary for the specific activity to reach $\frac{1}{2}$ its value. In the remainder of this article $\mathrm{T} \frac{1}{2}$ designates the slowest or third exponential component. contribution to endogenous (unlabeled) VMA made by epinephrine secretion. Nevertheless, in order to confirm this interpretation, the specific activity of VMA (VMA- ${ }^{3} \mathrm{H} / \mathrm{VMA}$ ) was contrasted with that of total metanephrines $\left(\mathrm{NM}-{ }^{3} \mathrm{H} / \mathrm{NM}+\mathrm{M}\right)$. Despite introduction of a component resulting from endogenous epinephrine metabolism entering into the calculation of total specific activity both of total metanephrines and VMA, the values for VMA remained considerably lower. That these differences in specific activities were not the result of instability of the tritium label during deamina-

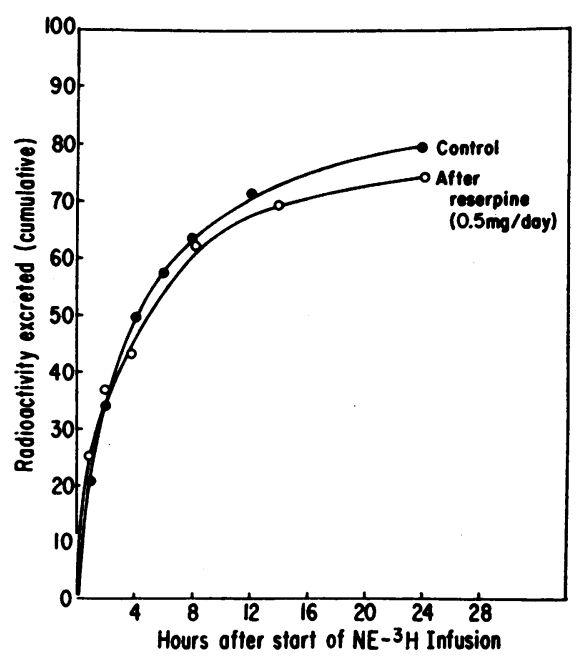

FIGURE 1 Cumulative excretion of tritium-labeled metabolites after intravenous administration of $\mathrm{NE}-{ }^{8} \mathrm{H}(0.02 \mu \mathrm{g} /$ $\mathrm{kg}$ per $\mathrm{min}$ ) for $1 \mathrm{hr}$; the effect of reserpine on the cumulative excretion (patient 1, Table I). 


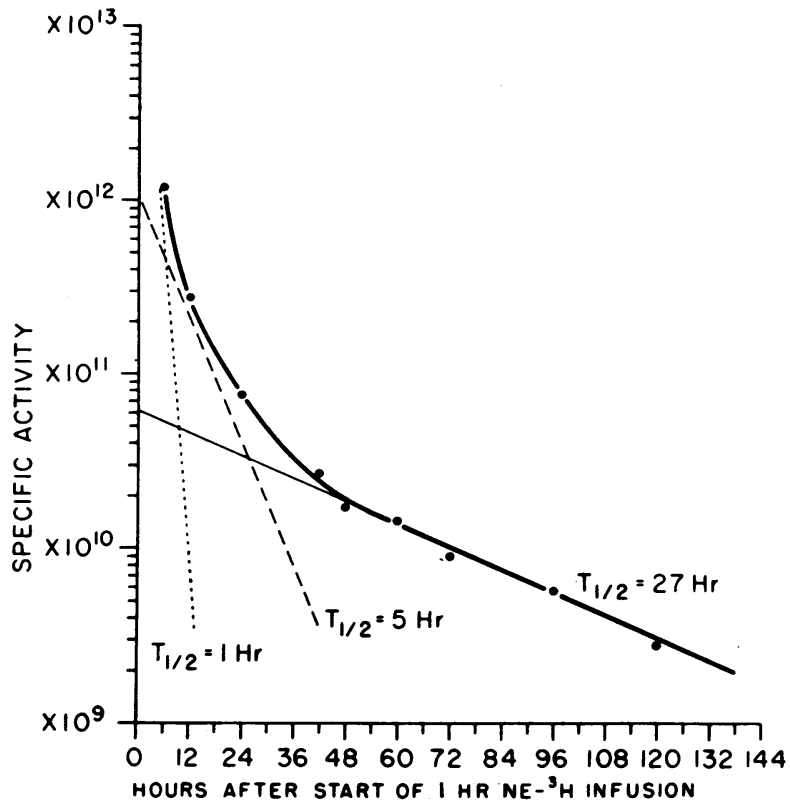

FIgURE 2 Decline of specific activity ( $\mathrm{dpm} / \mathrm{mm}$ ) expressed as the sum of three exponential functions (patient 2, Table I).

tion was evident from parallel experiments using $\mathrm{NE}^{-14} \mathrm{C}$. In an effort to verify that the administered $\mathrm{NE}-{ }^{-} \mathrm{H}$ was successfully labeling the adrenergic $\mathrm{NE}$ storage vesicles, and that the relatively lower specific activity of VMA stemmed from less adequate introduction of $\mathrm{NE}-{ }^{8} \mathrm{H}$ into this pool which preferentially degraded $\mathrm{NE}$ to VMA, rather than resulting solely from an unlabeled pool favoring degradation to deaminated products (i.e. central nervous system), $\mathrm{NE}-{ }^{8} \mathrm{H}$ turnover studies were performed before and during reserpine administration.

Reserpine, though failing at this dosage to affect significantly either the $24 \mathrm{hr}$ cumulative excretion of ${ }^{3} \mathrm{H}$ (Fig. 1) or the specific activity or $\mathrm{T}$ of $\mathrm{NE}$ or NM, resulted in a marked fall in the specific activities of VMA and G (Figs. 3 and 4, Table II). These striking changes in the specific activities of the deaminated catabolites relative to those of NE and NM, were not accompanied by any significant change in the excretion of the four major endogenous NE metabolites (Table II).

Repeat NE- ${ }^{8} \mathrm{H}$ metabolic studies of three subjects showed no significant change in any parameter.

\section{DISCUSSION}

The current studies were purposefully performed upon normal subjects of various ages, sex, and race who continued their usual activities throughout the period of observation. No attempt was made to establish subgroups with increased or decreased degrees of emotional stress or physical activity. Despite the avoidance of restrictions on daily activities commonly associated with modification of adrenergic activity, the present study revealed minimal variability. In fact, the results from repeat $\mathrm{NE}-{ }^{3} \mathrm{H}$ infusion studies failed to differ from those obtained during the original testing.

Although administration of $\mathrm{NE}-{ }^{8} \mathrm{H}$ failed to modify blood pressure or pulse rate, there was no question that the dosage was unphysiologic and disturbed the steady state. This was necessary in order to achieve adequate concentrations of isotope to permit measurement of specific activities of the various catabolites. Although some evidence accumulated suggesting reduction in the size of the $\mathrm{NE}-{ }^{3} \mathrm{H}$ dose resulted in a shorter period of equilibration and achievement of exponential declines in specific activity values before the 3rd day, assay of the labeled congeners was complicated by excessively low isotope concentrations. Limited attention was directed to the initial two exponential components since the degree to which they represented artifacts resulting from the disturbed steady state could not be readily ascertained (19). Measurement of specific activities every $6 \mathrm{hr}$ over a period of 9 days failed to reveal any change in the definitive (third component) exponent. The absence of a slower component suggested that equilibration had occurred and a steady state achieved in those pools labeled. Under the circumstances of these

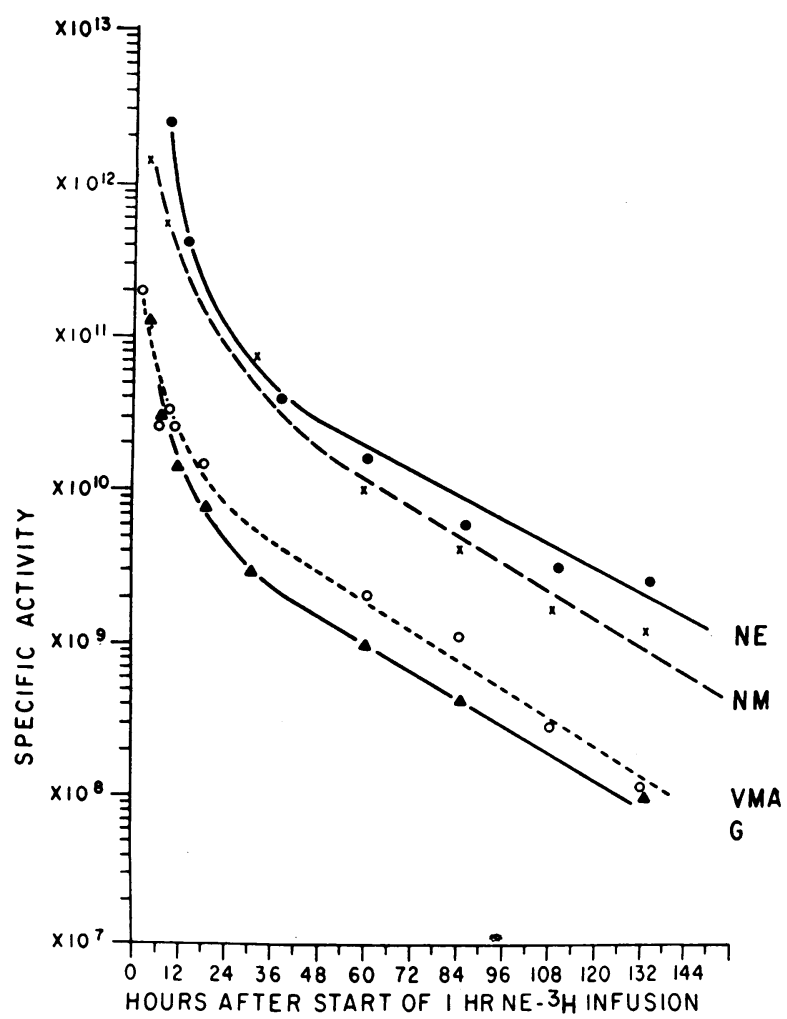

FIGURE 3 Relative specific activities (dpm/mm) of the major NE metabolites following administration of $\mathrm{NE}^{8} \mathrm{H}$ to a normal human subject (patient 3, Table I). 
studies one could not be certain whether or not each of the labeled pools established by the $\mathrm{NE}-{ }^{3} \mathrm{H}$ administration were indeed physiologic. Since the testing procedure temporarily elevated circulating $\mathrm{NE}$, artifactual pools could have resulted. Moreover, there is evidence that $\mathrm{NE}$ recently introduced into storage pools may be preferentially utilized (28). On the other hand, investigations by Costa et al. suggest that $\mathrm{NE}-{ }^{3} \mathrm{H}$ rapidly equilibrates with endogenous NE (25).

For each subject, the final exponential decline in specific activity of each catecholamine metabolite was found to be approximately the same. Since it was unlikely that the diverse catabolic processes possessed extremely similar rate constants, a more feasible explanation of these observations was that of a rate-limiting distribution pool responsible for introduction of labeled $\mathrm{NE}$ into perhaps unequally but at least more rapidly turning-over pools forming each of the catabolites. The occasional observation that the turnover for unchanged $\mathrm{NE}$ was slower than that for NM, VMA, or G might be related to a slower rate of release of labeled $\mathrm{NE}$ which differed slightly from that of the previously mentioned "distribution" pool. A second possibility that

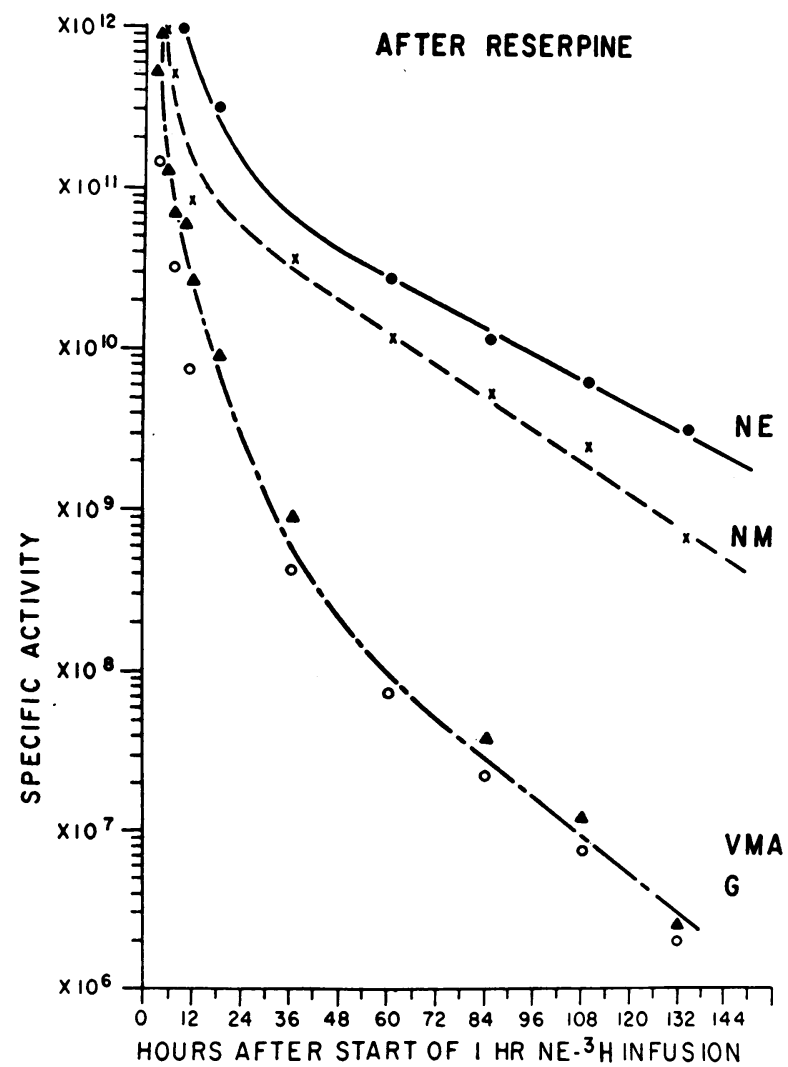

Figure 4 Effect of reserpine $(0.5 \mathrm{mg} /$ day $)$ upon the relative specific activities ( $\mathrm{dpm} / \mathrm{mm}$ ) of the major NE metabolites after the administration of $\mathrm{NE}-{ }^{8} \mathrm{H}$ to a normal human subject (patient 3 , Table I).
TABLE II

Excretion of the Major Endogenous Norepinephrine Metabolites*

\begin{tabular}{ccc}
\hline Metabolites & Control & $\begin{array}{c}\text { After } \\
\text { reserpine }(0.5 \mathrm{mg} / \text { day })\end{array}$ \\
\hline HVA & 2.10 & 2.54 \\
VMA & 0.94 & 1.03 \\
G & 1.14 & 1.22 \\
NE & 0.036 & 0.029 \\
NM & 0.067 & 0.073 \\
\hline
\end{tabular}

* Averages of 10 or more determinations on different urine specimens $(\mu \mathrm{g} / \mathrm{mg}$ creatinine).

could not be ruled out, was that of the existence of a slowly turning-over pool capable of $\mathrm{NE}-{ }^{8} \mathrm{H}$ uptake and resulting in preferential excretion of $\mathrm{NE}^{-} \mathrm{H}$ as opposed to its catabolites. Recent studies of the $\mathrm{NE}-{ }^{8} \mathrm{H}$-containing alumina eluate by paper chromatography in phenol: hydrochloric acid suggest the presence of minute quantities of labeled impurities which might result in an artifactual elevation of the $\mathrm{NE}^{-3} \mathrm{H} \mathrm{T}$.

In contradistinction to the similarity in turnover rates of the catabolites, their relative specific activities differed markedly and consistently from one another. That an unstable tritium label could be responsible for these observations was ruled out by parallel experiments employing NE- ${ }^{14} \mathrm{C}$. Since the specific activities of the deaminated catabolites were less than one-fifth those of $\mathrm{NE}$ and NM, the labeled NE could not have been distributed in the same fashion as endogenously synthesized NE. These data, though useful for determination of turnover rate of the labeled pool(s), do not offer a means whereby NE synthesis can be calculated. The differences in the relative specific activities suggest that NE- ${ }^{-} \mathrm{H}$ entered with difficulty the pool preferentially forming the deaminated products. These observations are analogous to those animal experiments wherein tyramine released relatively more labeled than unlabeled NE (29). On the other hand, a more uniform distribution of labeled catecholamine may eventually be possible, since reduction in isotope dosage lessens the difference in specific activities of the various catabolites (30).

Since it was unlikely that the $\mathrm{NE}-{ }^{-} \mathrm{H}$ passed the blood-brain barrier (31), the central nervous system could have served as a source of deaminated catabolites, explaining at least in part, the lower specific activity of these metabolites (32). In view of the apparent preferential reduction of vanilaldehyde in the brain (33), the blood-brain barrier might well represent the reason for G specific activity being minimally lower than that for VMA. However, the great difference between VMAand NM specific activities could hardly be interpreted in this manner. It was more likely that labeled NE was unable to reach and be incorporated within the so-called 
deep or reserpine-releasable stores. For that reason, studies were repeated in some subjects during reserpine administration. The marked decrease in the specific activities of VMA and G without a concomitant fall in those of NE and NM served as evidence that the label before drug administration had achieved some distribution within that pool preferentially catabolized to deaminated products and pharmacologically noteworthy by being reserpine releasable. Animal experiments indicated the anatomic confines of this pool to be the NE storage vesicles $(34,35)$.

A difference was also noted between the specific activities of G and VMA in almost every subject despite the presumption that both substances were derived from a common aldehyde precursor and the observation of similar $\mathrm{T} \frac{1}{2}$ values. Again, parallel studies with $\mathrm{NE}-{ }^{14} \mathrm{C}$ confirmed these findings. With the assumptions that no alternate pathway existed for the formation of $G$ and that the human central nervous system, unpenetrated by the labeled NE, produced little or no VMA, random samples from these normal human subjects were calculated to have derived $20-35 \%$ of their urinary G from the central nervous system. These figures are in agreement with those derived from animal studies (33).

Although various tissues possess differing NE turnover rates and the details of distribution of the labeled $\mathrm{NE}$ could not be evaluated in the current experiments, attention has been focused upon that turnover component reflecting the behavior of those tissues possessing the slowest turnover rate. Experiments by Chidsey " demonstrated that this component, as measured by changes in specific activity of $\mathrm{NE}$ in urine, could be correlated with human cardiac NE turnover. Berkowitz confirmed the similarity of NE turnover in the vasculature to that of the heart (36). Although human turnover information derived from $\mathrm{NE}-{ }^{3} \mathrm{H}$ administration might fail to elucidate the dynamics of catecholamine metabolism within those tissues or pool systems of interest to any specific investigator, there is no doubt that it sheds considerable light upon a pool located within tissues of physiologic and pharmacologic importance. Moreover, there is evidence that the ability to bind and turnover $\mathrm{NE}-{ }^{-} \mathrm{H}$ closely reflects the status of sympathetic activity $(37,38)$.

Large doses of reserpine may change the excretion of certain catecholamine catabolites (39). In the present study, a dosage of reserpine comparable to that used clinically and adequate to cause interference in adrenergic neurotransmission (40) resulted in a marked defect in $\mathrm{NE}$ metabolism as reflected by $\mathrm{NE}-{ }^{8} \mathrm{H}$ administration whereas no change in endogenous NE, VMA, NM, or $\mathrm{G}$ excretion was observed. As noted by DeQuattro and Sjoerdsma (41) using DOPA- ${ }^{3} \mathrm{H}$, such isotopic method-

\footnotetext{
${ }^{4}$ Chidsey, C. Personal communication.
}

ology broadens the information available concerning the pharmacologic action of various drugs upon human catecholamine metabolism.

The validity of labeled $\mathrm{NE}$ as a tracer for studies of NE metabolism, though amply confirmed in animal experiments and in correlative studies by Chidsey of heart muscle and urine ${ }^{4}$ came under scrutiny after observation of appreciably faster catecholamine metabolite turnover rates following administration of DOPA- ${ }^{3} \mathrm{H}$ to human subjects (41). This was puzzling since the data from Goodall's dopamine- ${ }^{14} \mathrm{C}$ experiments (42) are in agreement with the turnover rates observed in this investigation as well as the studies of Chidsey and Braunwald (18). A difference in the distribution $(43,44)$ and assay techniques, using a label which could enter catabolic pathways other than those stemming from NE, could account for the lower $T_{1}(41,45)$. It seems more probable that the inability to administer a dose of radioisotope sufficient to measure catecholamine metabolites after a time interval long enough for equilibration of the label, made appreciation of the definitive exponent difficult. Despite difference in methodology, these workers also observed that the NE turnover values in urine were similar to those in cardiac tissue.

\section{ACKNOWLEDGMENTS}

Dr. Gitlow was supported by grants HE 12648-01 (National Heart Institute) and RR-0071 (National Institutes of Health).

\section{REFERENCES}

1. Euler, U. S. von. 1946. A specific sympathomimetic ergone in adrenergic nerve fibers (sympathin) and its relation to adrenaline and noradrenaline. Acta Physiol. Scand. 12: 73 .

2. Armstrong, M. D., A. McMillan, and K. N. F. Shaw. 1957. 3-Methoxy-4-hydroxy-D-mandelic acid, a urinary metabolite of norepinephrine. Biochim. Biophys. Acta. 25: 422.

3. Gitlow, S. E., M. Mendlowitz, S. Khassis, G. Cohen, and J. Sha. 1960. The diagnosis of pheochromocytoma by determination of urinary 3-methoxy-4-hydroxymandelic acid. J. Clin. Invest. 39: 221.

4. Pisano, J. J. 1960. A simple analysis for normetanephrine and metanephrine in urine. Clin. Chim. Acta. 5: 406.

5. Axelrod, J., H. Weil-Malherbe, and R. Tomchick. 1959. The physiological disposition of ${ }^{3} \mathrm{H}$-epinephrine and its metabolite metanephrine. J. Pharmacol. Exp. Ther. 127: 251.

6. Goodall, McC., N. Kirshner, and L. Rosen. 1959. Metabolism of noradrenaline in the human. J. Clin. Invest. 38: 707.

7. Gitlow, S. E., M. Mendlowitz, E. Gall, R. L. Wolf, and N. Naftchi. 1960. Metabolism of $d l-\beta-\mathrm{H}^{8}$-norepinephrine in the human subject. Clin. Res. 8: 365 .

8. Gitlow, S. E., M. Mendlowitz, A. Smith, E. Gall, R. L. Wolf, and N. E. Naftchi. 1961. The dynamics of norepinephrine metabolism. In The Second Hahnemann Symposium on Hypertensive Disease. A. N. Brest and J. H. Moyer, editors. Lea and Febiger, Philadelphia, Pa. 335-342. 
9. Whitby, L. G., J. Axelrod, and H. Weil-Malherbe. 1961. The fate of $\mathrm{H}^{3}$-norepinephrine in animals. $J$. Pharmacol. Exp. Ther. 132: 193.

10. Wolfe, D. E., L. T. Potter, K. C. Richardson, and J. Axelrod. 1962. Localizing tritiated norepinephrine in sympathetic axons by electron microscopic autoradiography. Science (Washington). 138: 440.

11. Kopin, I. J., and E. K. Gordon. 1962. Metabolism of norepinephrine- $\mathrm{H}^{3}$ released by tyramine and reserpine. $J$. Pharmacol. Exp. Ther. 138: 351 .

12. Kopin, I. J., and E. K. Gordon. 1963. Metabolism of administered and drug released norepinephrine-7- $\mathrm{H}^{3}$ in the rat. J. Pharmacol. Exp. Ther. 140: 207.

13. Hertting, G., J. Axelrod, L. J. Kopin, and L. G. Whitby. 1961. Lack of uptake of catecholamines after chronic denervation of sympathetic nerves. Nature (London). 189: 66.

14. Hertting, G., L. T. Potter, and J. Axelrod. 1962. Effect of decentralization and ganglionic blocking agents on the spontaneous release of $\mathrm{H}^{3}$-norepinephrine. J. Pharmacol. Exp. Ther. 136: 289.

15. Axelrod, J. 1959. Metabolism of epinephrine and other sympathomimetic amines. Physiol. Rev. 39: 751.

16. Spector, S., P. A. Shore, and B. B. Brodie. 1960. Biochemical and pharmacological effects of the monoamine oxidase inhibitors, iproniazid, 1-phenyl-2-hydrazino-propane (JB 516) and 1-phenyl-3-hydrazinobutane. J. Pharmacol. Exp. Ther. 128: 15.

17. Gitlow, S., M. Mendlowitz, S. Wilk, E. K. Wilk, and N. Naftchi. 1964. Specific activities of norepinephrine (NE) and its major metabolites in urine following infusion of $d l-\beta-\mathrm{H}^{3}-\mathrm{NE}$ to five human subjects. Fed. Proc. 23: 280

18. Chidsey, C. A., and E. Braunwald. 1966. Sympathetic activity and neurotransmitter depletion in congestive heart failure. Pharmacol. Rev. 18: 685.

19. Costa, E., D. J. Bouillin, W. Hammer, W. Vogel, and B. B. Brodie. 1966. Interactions of drugs with adrenergic neurons. Pharmacol. Rev. 18: 577.

20. Gitlow, S. E., M. Mendlowitz, E. K. Wilk, S. Wilk, R. L. Wolf, and N. E. Naftchi. 1964. Plasma clearance of $d l-\beta-\mathrm{H}^{3}$-norepinephrine in normal human subjects and patients with essential hypertension. J. Clin. Invest. 43: 2009

21. Jaffé, M. (Method of). 1947. In Practical Physiological Chemistry. P. B. Hawk, B. L. Oser, and W. H. Summerson, editors. Blakeston Co., Philadelphia, $\mathrm{Pa}$. 839.

22. Anton, A. H., and D. F. Sayre. 1962. A study of the factors affecting the aluminum oxide trihydroxyindole procedure for the analysis of the catecholamines. $J$. Pharmacol. Exp. Ther. 138: 360.

23. Gitlow, S. E., M. Mendlowitz, E. K. Wilk, S. Wilk, R. L. Wolf, and L. M. Bertani. 1968. Excretion of catecholamine catabolites by normal children. J. Lab. Clin. Med. $72: 612$.

24. Wilk, S., S. E. Gitlow, M. Mendlowitz, M. J. Franklin, H. E. Carr, and D. D. Clarke. 1965. A quantitative assay for vanillylmandelic acid (VMA) by gas-liquid chromatography. Anal. Biochem. 13: 544.

25. Wilk, E. K., S. E. Gitlow, and L. M. Bertani. 1967. Modification of the Taniguchi method for the determination of normetanephrine and metanephrine. Clin. Chim. Acta. 20: 147.

26. Taniguchi, K., Y. Kakimoto, and M. D. Armstrong. 1964. Quantitative determination of metanephrine and normetanephrine in urine. J. Lab. Clin. Med. 64: 469.
27. Wilk, S., S. E. Gitlow, D. D. Clarke, and D. H. Paley. 1967. Determination of urinary 3-methoxy-4-hydroxyphenylethylene glycol by gas-liquid chromatography and electron capture detection. Clin. Chim. Acta. 16: 403.

28. Kopin, I. J., G. R. Breese, K. R. Krauss, and V. K. Weise. 1968. Selective release of newly synthesized norepinephrine from the cat spleen during sympathetic nerve stimulation. J. Pharmacol. Exp. Ther. 161: 271.

29. Potter, L. T., J. Axelrod, and I. J. Kopin. 1962. Differential binding and release of norepinephrine and tachyphylaxis. Biochem. Pharmacol. 11: 254.

30. Neff, N. H., T. N. Tozer, W. Hammer, E. Costa, and B. B. Brodie. 1968. Application of steady-state kinetics to the uptake and decline of $\mathrm{H}^{3}-\mathrm{NE}$ in the rat heart. J. Pharmacol. Exp. Ther. 160: 48.

31. Weil-Malherbe, H., L. G. Whitby, and J. Axelrod. 1961. The uptake of circulating $\left({ }^{3} \mathrm{H}\right)$ norepinephrine by the pituitary gland and various areas of the brain. $J$. Neurochem. 8: 55.

32. Udenfriend, S., and P. Zaltzman-Nirenberg. 1963. Norepinephrine and 3,4-dihydroxyphenethylamine turnover in guinea-pig brain in vivo. Science (Washington). 142: 394.

33. Maas, J. W., and D. H. Landis. 1968. In vivo studies of the metabolism of norepinephrine in the central nervous system. J. Pharmacol. Exp. Ther. 163: 147.

34. Carlsson, A., E. Rosengren, A. Bertler, and J. Nilsson. 1957. Effects of reserpine on the metabolism of catecholamines. In International Symposium on Psychotropic Drugs, Milan, 1957. S. Garattini, and B. Erspamer, editors. Elsevier Publishing Co., Amsterdam. 363-372.

35. Iversen, L. L. 1967. The uptake and storage of noradrenaline. In Sympathetic Nerves. Cambridge University Press, Cambridge, England. 204.

36. Berkowitz, B. A. 1970. Studies on the disposition, regulation and synthesis of catecholamines in blood vessels. Fed. Proc. 29: 278. (Abstr.)

37. Gordon, R., S. Spector. A. Sjoerdsma, and S. Udenfriend. 1966. Increased synthesis of norepinephrine and epinephrine in the intact rat during exercise and exposure to cold. J. Pharmacol. Exp. Ther. 153: 440.

38. Reid, W. D., L. Volicer, and B. B. Brodie. 1967. The effect of drugs on the turnover rate of norepinephrine in heart. Fed. Proc. 26: 463.

39. Bozzi, R., A. Bruno, and A. Allegranza. 1965. Urinary metabolites of some monoamines and clinical effects under reserpine and chlorpromazine. Brit. J. Psychiat. $111: 176$.

40. Zaimis, E. 1964. Pharmacology of the autonomic nervous system. Ann. Rev. Pharmacol. 4: 365.

41. DeQuattro, V., and A. Sjoerdsma. 1968. Catecholamine turnover in normotensive and hypertensive man: effects of antiadrenergic drugs. J. Clin. Invest. 47: 2359.

42. Goodall, McC., and H. Alton. 1968. Metabolism of 3hydroxytyramine (dopamine) in human subjects. Biochem. Pharmacol. 17: 905.

43. Persson, T., and B. Waldeck. 1968. The use of ${ }^{3} \mathrm{H}$-Dopa for studying cerebral catecholamine metabolism. Acta Pharmacol. Toxicol. 26: 363.

44. Wurtman, R. J., I. J. Kopin, and J. Axelrod. 1963. Thyroid function and cardiac disposition of catecholamines. Endocrinology. 73: 63.

45. Persson, T., and B. Waldeck. 1970. A source of error in catecholamine turnover studies with labelled DOPA. Acta Pharmacol. Toxicol. 28: 466. 